\title{
Forecasting Service Quality Dynamics Based on Integrated Method with GM(1,1) Model and Markov Chain
}

\author{
Qingliang MENG, Zhijie Sasha DONG, Lin HE, Jing DONG
}

\begin{abstract}
Dynamics of quality attributes derived from Kano model has been recognized as one of the most interesting and fruitful developments of attractive quality theory. The purpose of this study is to propose an integrated method with $\mathrm{GM}(1,1)$ model and Markov chain to forecast the dynamics of service quality attributes with limited data and explore the existence of the alternative life cycles. Further, an empirical study of the express delivery industry in China is conducted at four points of time (the year of $2008,2010,2012$, and 2013 ) to verify the feasibility of the method. This study not only provides a quantitative method for forecasting the dynamics of service quality attributes with limited information, but also gives evidence for the existence of alternative life cycles of service quality attributes.
\end{abstract}

Keywords: dynamics of quality attributes; express delivery service; GM(1,1) model; Kano model; life cycle of quality attribute; Markov chain

\section{INTRODUCTION}

The advance of information technology and fierce competition in marketplace has changed the nature of business operations dramatically. Customers have largely evolved from their past role as passive buyers to value cocreators in the value chain [1]. Given these changes, companies must re-conceptualize their relationships with customers to gain competitive advantages. Specifically, a firm's success largely depends on its ability to adopt customer perspectives, detect customer requirements, and create value for customers. Meanwhile, the requirements of diverse customers evolve dynamically, compelling companies to adapt and refine salient characteristics of their products and services. Kano model is one of the most effective methods for enterprises to identify customer requirements. Considering the recognition of the nonlinear relationship between a product's performance and customer satisfaction, Kano model categorizes quality attributes into five categories: (i) must-be, (ii) onedimensional, (iii) attractive, (iv) indifferent, and (v) reverse quality attribute $[2,3]$.

As a customer-driven tool, Kano model has been widely used to analyse customer requirement, manage product/service quality and other practices [4-6]. This theory shows that the role of quality attributes conceptually changes over time [3]. Löfgren and Witell [4] highlighted that the concept of quality life cycles is one of the most interesting and fruitful developments in Kano model. However, only limited researches provide guidance on how the state of quality attributes changes over time and what the alternative life cycles for quality attributes should be $[7,4]$.

Kano [3] argued that there are two specific life-cycles: (i) Successful quality attributes life-cycle, which takes the form of indifferent $\rightarrow$ attractive $\rightarrow$ one-dimensional $\rightarrow$ must-be $(\mathrm{I} \rightarrow \mathrm{A} \rightarrow \mathrm{O} \rightarrow \mathrm{M})$, and (ii) Flavour-of-the-month quality attributes life-cycle, which takes the form of indifferent $\rightarrow$ one-dimensional $\rightarrow$ indifferent $(\mathrm{I} \rightarrow \mathrm{O} \rightarrow \mathrm{I})$. He provided an empirical support from the quality attributes dynamics of the remote-control device for a television set. Nilsson-Witell et al. [7] provided additional evidence through the demonstration that customers are largely indifferent towards e-services before they perceive them as attractive purchase options. Zhao et al. [8] contended that the quality attributes categories changed over time, and showed that three eighths quality attributes of web site interactivity changed within a period of 18 months. However, they failed to identify the specific lifecycle of quality attributes. Löfgren et al. [9] identified three quality attributes life-cycles of Kano model: successful quality attributes, flavour-of-the-month quality attributes, and stable quality attributes. They also extended the theory of attractive quality by identifying the reverse movement of certain quality attributes. Specifically, they found that quality attributes can move backwards in the life-cycle through various mechanisms (e.g., changes in product design). To address the dynamics of quality attributes in the Kano model, Raharjo [10, 11] proposed a compositional double exponential smoothing method to predict customers' future needs to incorporate them into QFD for multiple product design.

The literature on dynamics of quality attributes in Kano model is sparse. Only Kano [3], Nilsson-Witell and Fundin [7], Zhao and Dholkia [8], and Löfgren et al. [9] have provided empirical evidence for the presence of quality attributes life-cycles and given proofs to the dynamics of quality attributes in Kano model. However, their discussions on dynamics are domains specific, which may not be generalized to other fields. Moreover, they have overlooked difficulties in using quantitative approaches to forecast the dynamics of quality attributes. Forecasting future quality attributes' transition states is useful to tackle customer preference's change during product innovation process, and to develop the competitive service as an adapt to the rapid changing market today.

Many analytical models have been employed to forecast the dynamics of quality attributes. Some commonly adopted methods include statistical models, such as compositional double exponential smoothing method [11], fuzzy trend analysis [12] and artificial intelligence (AI) models [13]. Different models have different requirements on the amount of historical data to be used, and the prediction accuracy depends on the property of the data. The classification of quality attributes has been identified by a complicated process, including Kano survey, Kano evaluation and Kano results analysis, and it will take a company plenty of time and cost. To select 
an efficient and cost-effective method for predicting dynamics of quality attributes with insufficient data is necessary but challengeable.

To address the issues outlined above, we suggest an integrated method based on Grey-Markov chain model [14] to predict the dynamics of service quality attributes from Kano model with limited data. The major contributions we have made beyond the method proposed by Song et al. [14] include: (i) We use the form of point estimation in forecasting process, so as to obtain the Kano model classification results of quality attributes accurately; (ii) With the prediction quality attributes dynamics states, the life cycles of quality attributes are identified and tested empirically in express delivery industries.

Thus, we focus on tackling the following issues: (i) How can we forecast the dynamics of service quality attributes from Kano model with limited data? (ii) Can we provide evidences to show the existence of alternative life cycles of quality attributes identified by previous literature?

\section{KANO MODEL AND DYNAMICS OF QUALITYATTRIBUTES}

Kano model has been widely used in industries as an effective tool to classify and prioritize quality attributes. However, Kano model has some disadvantages [15]. In particular, the traditional Kano survey does not allow uncertainty in customer's response when answering survey questions. However, most people are prone to indecisiveness and fuzziness. Thus, scholars such as Lee and Huang [16], Wang [17], and Meng et al. [18] proposed the fuzzy Kano model through integrated fuzzy set theory. The fuzzy Kano model they proposed is better at mimicking a realistic cognitive process in practice, since an evaluator's multifaceted feelings could be expressed by the possibility degrees among multiple items. Due to its advantages, in this study we have adapted the fuzzy Kano model to elicit customers' perception and determine the category of each of the service quality attributes.

Nevertheless, the dynamics of quality attributes may take place in a rapidly changing environment. For example, what now delights the customer may become an expected or indifferent quality attribute in the future. It is of great importance to consider changes of quality attributes over time to improve and develop products' or services' quality. Kano [3] first demonstrated that the quality attributes' categorization is not absolutely invariable but instead it changes with time. He pioneered the theory of quality attributes life cycles. Tab. 1 summarizes the literature relevant to this stream of research.

It is shown that few pieces of literature have endeavored to forecast the quality dynamics and empirically study the quality attributes life cycles. In fact, exploring the quality dynamics and life cycles is the most interesting and important area in extending Kano theory [4, 19]. Thus, Raharjo et al. [11] proposed the compositional double exponential smoothing (CDES) method to model the Kano categories change over time. However, such a time series forecasting method is suitable for short-term prediction, and a large sample size is necessary. As the traditional Kano model requires significant time and cost to amass the necessary data, it is imperative that we can find an efficient forecasting method to predict the dynamics of quality attributes, so as to effectively and timely detect customer preference change even if the data is extremely limited. Song et al. [14] proposed an integrated method of grey theory and Markov chain to predict customer requirement states. The method provided the interval form of customer requirement forecasting to get higher accuracy with fewer data. However, they ignored to identify the life cycles of quality attributes.

Table 1 An overview of related literature

\begin{tabular}{|c|c|c|c|c|c|c|c|}
\hline Authors & Research focus & Time duration & Dynamics & Specific life cycles & Evidence & Forecasting & Method \\
\hline Kano, N. [3] & $\begin{array}{l}\text { Remote-control } \\
\text { device for a } \\
\text { television set }\end{array}$ & $\begin{array}{l}1983,1989 \text { and } \\
1998\end{array}$ & $\mathrm{Y}$ & $\begin{array}{l}\text { - Successful quality } \\
\text { - Flavor-of-the-month } \\
\text { quality }\end{array}$ & $\mathrm{Y}$ & $\mathrm{N}$ & Survey \\
\hline $\begin{array}{l}\text { Nilsson-Witell, L. \& } \\
\text { Fundin, A. [7] }\end{array}$ & E-services & Not mentioned & $\mathrm{Y}$ & - Successful quality & $\mathrm{Y}$ & $\mathrm{N}$ & $\begin{array}{l}\text { General linear } \\
\text { model }\end{array}$ \\
\hline $\begin{array}{l}\text { Zhao, M. \& } \\
\text { Dholkia, R. R. [8] }\end{array}$ & $\begin{array}{l}\text { Website interactivity } \\
\text { attributes }\end{array}$ & $\begin{array}{l}\text { 18-Month time } \\
\text { interval }\end{array}$ & $\mathrm{Y}$ & $\mathrm{N}$ & $\mathrm{Y}$ & $\mathrm{N}$ & Statistics \\
\hline Löfgren, M. et al. [9] & $\begin{array}{l}\text { Particular packaging } \\
\text { attributes }\end{array}$ & 2003 and 2009 & $\mathrm{Y}$ & $\begin{array}{l}\text { - Successful quality } \\
\text { - Flavor-of-the-month } \\
\text { quality } \\
\text { - Stable quality, } \\
\text { and other reverse } \\
\text { movement of certain } \\
\text { quality attributes }\end{array}$ & $\mathrm{Y}$ & $\mathrm{N}$ & $\begin{array}{l}\text { Survey and } \\
\text { statistics }\end{array}$ \\
\hline Raharjo, H. et al. [11] & $\begin{array}{l}\text { Multiple Product } \\
\text { design for mobile } \\
\text { computing }\end{array}$ & $\begin{array}{l}\text { Survey } \\
\text { conducted every } \\
\text { two months, last } \\
\text { for } 9 \text { time } \\
\text { intervals }\end{array}$ & $\mathrm{Y}$ & $\mathrm{N}$ & $\mathrm{Y}$ & $\mathrm{Y}$ & $\begin{array}{l}\text { compositional } \\
\text { double } \\
\text { exponential } \\
\text { smoothing } \\
\text { (CDES) method }\end{array}$ \\
\hline Song, W. et al. [14] & A mobile phone & $\begin{array}{l}\text { In the past five } \\
\text { quarters }\end{array}$ & $\mathrm{Y}$ & $\mathrm{N}$ & $\mathrm{N}$ & $\mathrm{Y}$ & $\begin{array}{l}\text { Grey-Markov } \\
\text { chain }\end{array}$ \\
\hline This paper & $\begin{array}{l}\text { Express delivery } \\
\text { service }\end{array}$ & $\begin{array}{l}2008,2010, \\
2012, \text { and } 2013\end{array}$ & $\mathrm{Y}$ & $\mathrm{Y}$ & $\mathrm{Y}$ & $\mathrm{Y}$ & $\operatorname{MCMG}(1,1)$ \\
\hline
\end{tabular}

\section{PREDICTING QUALITY ATTRIBUTES DYNAMICS USING MCGM(1,1) MODEL}

Service quality is significantly related to the service processes and service personnel; some core service processes may be more important than others, while certain key personnel may be vital to the customers. Customers' preference and taste of service are usually different in various market segments at different life cycles of service. Therefore, it is very difficult to determine a definite state trend of service quality attributes dynamics in real life. In this respect, the prediction for service quality attributes 
dynamics is a grey system in nature. Thus, it is appropriate to apply the $\operatorname{GM}(1,1)$ model to forecast future service quality attributes states. However, the prediction accuracy of $\operatorname{GM}(1,1)$ is low when data fluctuations are immense [19]. While Markov chain model makes use of the transition probabilities to predict the evolution of stochastic system, it is suitable to predict the data sequence even facing high fluctuations [19]. Therefore, it is logical to integrate $\operatorname{GM}(1,1)$ and Markov chain model (i.e., $\operatorname{MCGM}(1,1))$ to forecast the dynamics of service quality attributes with limited data.

Fig. 1 shows the framework of $\operatorname{MCGM}(1,1)$ to predict dynamics of service quality attributes with limited data. It involves several sub-processes: identification of service quality attributes, classification of service quality attributes based on fuzzy Kano model and construction of $\operatorname{MCGM}(1,1)$ prediction model.

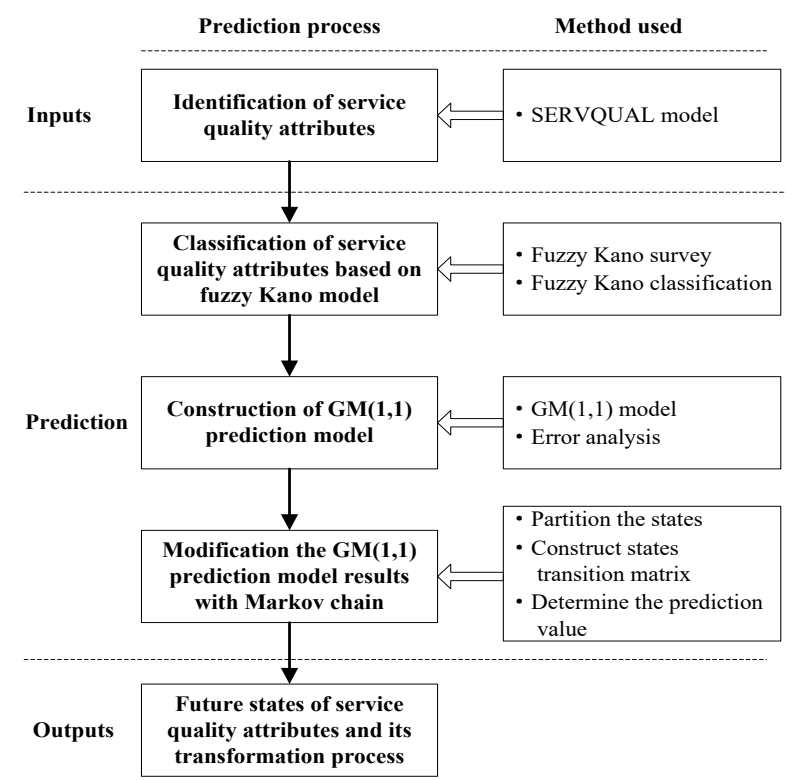

Figure1 The framework of $\operatorname{MCGM}(1,1)$ to predict dynamics of service quality attributes

\subsection{Identification of Service Quality Attributes}

The extraction and identification of service quality attributes is the foundation of the Kano model. Service qualities have distinctive features which are different from general products, including: (1) Intangibility: service is an abstract product which is intangible. (2) Inseparability: service is inseparable from its original source. (3) Heterogeneity: the same service could have different standards due to the differences of attendants, timings, or locations. (4) Perishability: a service cannot be stored. So it is very important to find an effective way to translate customer requirements into a set of service quality attributes from the customer perspective. The SERVQUAL model can be used to identify and extract customer service quality attributes by listening to the voice of customers [20].

\subsection{Classification of Service Quality Attributes Based on Fuzzy Kano Model}

To understand the uncertainty and indecision of customer psychology when buying the service, we adapt a fuzzy Kano model to objectively classify the quality attributes [16, 18]. A fuzzy Kano questionnaire is designed. The largest difference is that only one answer will be permitted in the traditional Kano questionnaire, but interviewees can choose various answers in the fuzzy Kano model questionnaire. It flexibly allows interviewees to give diversification answers, which is more reasonable and applicable to express customers' real perception. Based on the information obtained of customer requirements, the classification of service quality attributes can be derived using the fuzzy Kano model [18].

\subsection{Construction MCGM(1,1) Prediction Model}

In the following section, the derivation of $\operatorname{MCGM}(1,1)$ is briefly described [21].

Assume that the original series of data with $n$ entries is

$X^{(0)}=\left\{x^{(0)}(1), x^{(0)}(2), \ldots, x^{(0)}(k), \ldots, x^{(0)}(n)\right\}$

where raw material $X^{(0)}$ stands for the non-negative original historical time series data.

Construct $X^{(1)}$ by one time accumulated generating operation (1-AGO), which is

$X^{(1)}=\left\{x^{(1)}(1), x^{(1)}(2), \ldots, x^{(1)}(k), \ldots, x^{(1)}(n)\right\}$

Where,

$X^{(1)}(k)=\sum_{i=1}^{k} X^{(0)}(i), \quad k=1,2, \ldots, n$

Construct the mean sequence $Z^{(1)}$ with respect to $X^{(1)}$, which is

$$
Z^{(1)}=\left(z^{(1)}(2), z^{(1)}(3), \ldots, z^{(1)}(k), \ldots, z^{(1)}(n)\right)
$$

Where

$z^{(1)}(k)=\frac{x^{(1)}(k)+x^{(1)}(k-1)}{2}$

and $k=2,3, \ldots, n$.

The differential equation of the grey model can be obtained

$$
x^{(0)}(k)+a z^{(1)}(k)=b
$$

where $k=2,3, \ldots, n$.

To do this, using the least square method, parameters $a$ and $b$ can be written as

$\hat{a}=\left[\begin{array}{l}a \\ b\end{array}\right]=\left(B^{\mathrm{T}} B\right)^{-1} B^{\mathrm{T}} Y$

where $B$ and $Y$ are defined as follows

$$
B=\left[\begin{array}{cc}
-z^{(1)}(2) & 1 \\
-z^{(1)}(3) & 1 \\
\vdots & \vdots \\
-z^{(1)}(n) & 1
\end{array}\right], \quad Y=\left[\begin{array}{c}
x^{(0)}(2) \\
x^{(0)}(3) \\
\vdots \\
x^{(0)}(n)
\end{array}\right]
$$


where "^" represents the grey predicted value complemented the corresponding initial condition.

The relevant whitenization of Eq. (6) is defined as $\frac{\mathrm{d} x^{(1)}}{\mathrm{d} t}+a x^{(1)}=b$, and its time response function can be obtained

$\hat{x}^{(1)}(k+1)=\left(x^{(0)}(1)-\frac{b}{a}\right) \mathrm{e}^{-a t}+\frac{b}{a}$

The time response function of Eq. (6) can be written as

$$
x^{(1)}(t)=\left(x^{(1)}(1)-\frac{b}{a}\right) \mathrm{e}^{-a t}+\frac{b}{a}
$$

where $k=1,2, \ldots, n$.

Hence, the desired prediction output at $k$ step can be estimated by inverse accumulated generating operation (1IAGO) which is defined as

$\hat{x}^{(0)}(k+1)=\hat{x}^{(1)}(k+1)-\hat{x}^{(1)}(k)$

where $k=1,2, \ldots, n$.

Assume that the original series of data is $x^{(0)}=\left\{x^{(0)}(1), x^{(0)}(2), \ldots, x^{(0)}(k), \ldots, x^{(0)}(n)\right\}$.

The forecast series of data is

$$
\hat{x}^{(0)}=\left\{\hat{x}^{(0)}(1), \hat{x}^{(0)}(2), \ldots, \hat{x}^{(0)}(k), \ldots, \hat{x}^{(n)}(n)\right\}
$$

The residual series can be expressed as

$$
\begin{aligned}
& \varepsilon^{(0)}=\{\varepsilon(1), \varepsilon(2), \ldots, \varepsilon(k), \ldots, \varepsilon(n)\}= \\
& =\left\{x^{(0)}(1)-\hat{x}^{(0)}(1), x^{(0)}(2)-\hat{x}^{(0)}(2), \ldots\right. \\
& \left.\ldots, x^{(0)}(k)-\hat{x}^{(0)}(k), \ldots, x^{(0)}(n)-\hat{x}^{(0)}(n)\right\}
\end{aligned}
$$

The relative error series is defined as

$$
\Delta=\left\{\left|\frac{\varepsilon(1)}{x^{(0)}(1)}\right|,\left|\frac{\varepsilon(2)}{x^{(0)}(2)}\right|, \ldots,\left|\frac{\varepsilon(k)}{x^{(0)}(k)}\right|, \ldots,\left|\frac{\varepsilon(n)}{x^{(0)}(n)}\right|\right\}=\left\{\Delta_{k}\right\}_{1}^{n}(14)
$$

Relative error compares the real and predicted values at specific time $k$, and can be defined as

$$
\Delta_{k}=\left|\frac{\varepsilon(k)}{x^{(0)}(k)}\right|
$$

The total model precision can be defined by average relative error as follows

$$
\bar{\Delta}=\frac{1}{n} \sum_{k=1}^{n} \Delta_{k}
$$

For a given $\alpha$, when $\bar{\Delta}<\alpha$ and $\Delta_{n}<\alpha$ can be fulfilled simultaneously, then the grey model will be defined as qualified residual model.
For original data series, use $\operatorname{GM}(1,1)$ model to obtain the predicted value $\hat{x}^{(0)}(i)$, the residual error $\varepsilon(i)$ can also be obtained:

$\varepsilon(i)=x^{(0)}(i)-\hat{x}^{(0)}(i)$

Assume that there exists some regular information in the residual error series of $\operatorname{GM}(1,1)$. We can establish Markov state transition matrices, $r$ states are defined for each time step. Thus the dimension of the transition matrix is $r \times r$. The residual errors are partitioned into $r$ equal portions called states. Each state is an interval whose width is equal to a fixed portion of the range between the maximum and the minimum of the whole residual error. Then, the actual error can be classified into the following states.

Let $S_{i j}$ be the $j^{\text {th }}$ state of the $i^{\text {th }}$ time step

$S_{i j} \in\left[L_{i j}, U_{i j}\right], j=1,2, \ldots, r$

where $L_{i j}$ and $U_{i j}$ are the lower boundary and upper boundary of the $j^{\text {th }}$ state for the $i^{\text {th }}$ time step of the residual error series.

$$
\begin{aligned}
& L_{i j}=\min \varepsilon(i)+\frac{j-1}{r}(\max \varepsilon(i)-\min \varepsilon(i)) \\
& U_{i j}=\min \varepsilon(i)+\frac{j}{r}(\max \varepsilon(i)-\min \varepsilon(i))
\end{aligned}
$$

Establishment of transition probability matrix of state. If the transition probability of state is written as

$$
P_{i j}^{(m)}=\frac{M_{i j}^{(m)}}{M_{i}}, j=1,2, \ldots, r
$$

where $P_{i j}^{(m)}$ is the probability of transition from state $i$ to $j$ by m steps. $M_{i j}^{(m)}$ is the transition times from state $i$ to $j$ by $\mathrm{m}$ steps and $M_{i}$ is the number of data belonging to the ith state. Because the transition for the last $m$ entries of the series is indefinable, $M_{i}$ should be counted by the first as n$m$ entries; $n$ is the quantity of entries of the original series. Then, the transition probability matrix of state can be written as

$$
\boldsymbol{P}^{(m)}=\left[\begin{array}{cccc}
P_{11}^{(m)} & P_{12}^{(m)} & \cdots & P_{1 r}^{(m)} \\
P_{21}^{(m)} & P_{22}^{(m)} & \cdots & P_{2 r}^{(m)} \\
\vdots & \vdots & \vdots & \vdots \\
P_{r 1}^{(m)} & P_{r 2}^{(m)} & \vdots & P_{r r}^{(m)}
\end{array}\right]
$$

The transition probability matrix of states $\boldsymbol{P}^{(m)}$ reflects the transition rules of the system. The transition probability of states $P_{i j}^{(m)}$ reflects the probability of transition from initial state $\mathrm{i}$ to probable state $\mathrm{j}$ by $\mathrm{m}$ steps. It is the foundation of prediction by the Markov probability matrix. For example, consider $m=1$ and the maximum transition step is 1 . Then, $P(1)$ can be obtained. If the predicted 
original data is located in the ith state, the predicted data of next step is calculated by the row vector of transition probability states $P_{i j}^{(1)}$.

Obtaining the predicted value. The residual error series $\varepsilon(i)$ is divided into $r$ states, and then there is $r$ transition probability row vectors. The possibilities of a certain error state for the next step are obtained by the probabilities in $r$ row vectors, denoted as $\left\{a_{i}(T), i=1,2, \ldots, r\right\}$ at time step $T$. Define the centers of $r$ states as $\left\{v_{i}, i=1,2, \ldots, r\right\}$. Then, the predicted value for the next step is

$$
\tilde{x}^{(0)}(T+1)=\hat{x}^{(0)}(T+1)+\sum_{i=1}^{r} a_{i}(T) v_{i}
$$

Where

$$
a^{(T)}=\left[a_{1}(T), a_{2}(T), \ldots, a_{r}(T)\right]=a^{(T-1)} R^{(m)}
$$

And

$$
\left\{\begin{array}{c}
a^{(T+1)}=a^{(T)} R^{(m)} \\
a^{(T+2)}=a^{(T+1)} R^{(m)} \\
\vdots \\
a^{(T+k)}=a^{(T+k-1)} R^{(m)}
\end{array}\right\}
$$

Where $m=1$.

\section{AN EMPIRICAL STUDY}

To illustrate the usefulness of the proposed method in predicting the quality attributes dynamics, we conduct an empirical study in the express delivery industry in China. The growth of internet shopping and e-commerce has changed consumers' attitudes towards express delivery service. Consumers have shopped online more frequently, which significantly boosts the express industry's business and also puts up a higher force to satisfy the uncertain requirements on service quality. Exploring the dynamics of express service quality attributes will benefit firms to improve operation management and enhance productivity in the future.

\subsection{Questionnaire Design and Data Collection}

Deriving from the research work of Meng et al. [18], and discussions with experts and express delivery customers, we identify nine quality attributes to measure the express industry service quality (See Tab. 2).

Table 2 Service quality attributes

\begin{tabular}{|c|l|l|}
\hline No. & $\begin{array}{c}\text { Description of service quality } \\
\text { attributes }\end{array}$ & \multicolumn{1}{c|}{ Benefits provided } \\
\hline$f_{1}$ & On time delivery & Responsiveness \\
\hline$f_{2}$ & Door-to-door pick up & Convenience \\
\hline$f_{3}$ & Quality assurance & Safety, reliability \\
\hline$f_{4}$ & Tracking & Accuracy \\
\hline$f_{5}$ & Membership benefits & Loyalty \\
\hline$f_{6}$ & Complaints handled timely & Reliability, safety \\
\hline$f_{7}$ & Low price & Added value \\
\hline$f_{8}$ & High quality staff & Efficient communication \\
\hline$f_{9}$ & Free storage within 7 days & Safety, convenience \\
\hline
\end{tabular}

We design the fuzzy Kano questionnaire. It starts with respondent's demographic information such as age, gender, occupations, income levels and the frequency of usage of the express service. The main questionnaire focuses on the nine items listed in Tab. 2. Recall that the respondent can specify percentage matching the intensity he/she deems appropriate. The questionnaire includes both functional and dysfunctional forms, but unlike traditional Kano model using binary data, the fuzzy Kano model questionnaire allows respondents to express their multifeelings by the possibility degrees among multiple items.

The questionnaire administration and field work took place through four periods. We were given access to potential respondents based on the following criteria: (i) respondents who frequently use the express industry service; and (ii) respondents who are among the enterprise's database. Questionnaires were distributed in two ways: face-to-face and e-mail. In each time, 120 questionnaires through face-to-face and 100 questionnaires

\begin{tabular}{|c|c|c|c|c|c|c|c|}
\hline \multirow{2}{*}{ Period } & \multirow{2}{*}{ Time interval } & \multicolumn{2}{|c|}{ E-mail } & \multicolumn{2}{|c|}{ Face-to-face } & \multirow{2}{*}{ Questionable } & \multirow{2}{*}{$\begin{array}{c}\text { Effective rate } \\
(\%)\end{array}$} \\
\hline & & Issued & Retrieved & Issued & Retrieved & & \\
\hline$P_{1}$ & $2008.3 .10-5.31$ & 100 & 75 & 120 & 98 & 18 & 70.45 \\
\hline$P_{2}$ & $2010.7 .3-10.15$ & 100 & 80 & 120 & 90 & 13 & 71.36 \\
\hline$P_{3}$ & $2012.4 .10-6.30$ & 100 & 73 & 120 & 102 & 11 & 74.55 \\
\hline$P_{4}$ & $2013.3 .18-5.31$ & 100 & 69 & 120 & 105 & 14 & 72.73 \\
\hline
\end{tabular}
via e-mail were issued (see Tab. 3).

Table 3 The statistics results of the questionnaires

\subsection{Fuzzy Kano Quality Attributes Classification}

Using the fuzzy Kano model, we strive to match the quality attribute with one of the Kano categories (e.g. A: attractive; $\mathrm{O}$ : one-dimensional; $\mathrm{M}$ : must-be and $\mathrm{I}$ : indifferent). The classification results are summarized in Tab. 4, which takes the maximum membership degree value as the classification result of each quality attribute. Tab. 4 shows that attributes $f_{1}$ (On time delivery) and $f_{7}$ (Low price) have not changed over the four time periods; while other quality attributes are dynamic and have changed to some degrees.

\subsection{Predicting the Dynamics of Service Quality Attributes Using GM(1,1)}

To predict the changes of quality attribute over time, we take $f_{9}$ (Free storage within 7 days) as an example and use the following five steps to predict the dynamics.

(1) Construct the original series and its 1-AGO series

The original series of four different attributes of $f_{9}$ can be obtained from Tab. 4 : 
$X_{i}^{(0)}=\left\{x_{i}^{(0)}(1), x_{i}^{(0)}(2), \ldots, x_{i}^{(0)}(n)\right\}$

$i=M, A, I, O \quad N=1,2,3,4$

$X_{M}^{(0)}=\{0.2468,0.2763,0.3013,0.3457\}$

$X_{A}^{(0)}=\{0.1948,0.2171,0.2051,0.2099\}$

$X_{I}^{(0)}=\{0.1818,0.1908,0.2308,0.2222\}$

$X_{O}^{(0)}=\{0.3766,0.3158,0.2628,0.2222\}$

According to Eq. (3), the corresponding I-AGO series can be obtained as

$X_{M}^{(1)}=\{0.2468,0.5231,0.8244,1.1701\}$

$X_{A}^{(1)}=\{0.1948,0.4119,0.6170,0.8269\}$

$X_{I}^{(1)}=\{0.1818,0.3726,0.6034,0.8256\}$

$X_{O}^{(1)}=\{0.3766,0.6924,0.9552,1.1774\}$
(2) Calculate the parameters $a$ and $b$

According to Eq. (7), the model parameters $a$ and $b$ can be written as

$$
\left(\begin{array}{cc}
-a_{M} & b_{M} \\
-a_{A} & b_{A} \\
-a_{I} & b_{I} \\
-a_{O} & b_{O}
\end{array}\right)=\left(\begin{array}{cc}
0.1138 & 0.2298 \\
-0.0173 & 0.2196 \\
0.0704 & 0.1799 \\
-0.1762 & 0.4094
\end{array}\right)
$$

(3) Construct the time response function

Being repeated above steps, the time response function will be solved by Eq. (9), which is shown as follows:

$$
\begin{aligned}
& \hat{x}_{M}^{(1)}(k)=3.1894 \cdot \mathrm{e}^{0.1138(k-4)}-2.0193 \\
& \hat{x}_{A}^{(1)}(k)=-11.8677 \cdot \mathrm{e}^{-0.0173(k-4)}+12.6936 \\
& \hat{x}_{I}^{(1)}(k)=3.3810 \cdot \mathrm{e}^{0.0704(k-4)}-2.5554 \\
& \hat{x}_{O}^{(1)}(k)=-1.1461 \cdot \mathrm{e}^{-0.1762(k-4)}+2.3235
\end{aligned}
$$

\begin{tabular}{|c|c|c|c|c|c|c|c|c|c|c|c|c|c|c|}
\hline & \multicolumn{7}{|c|}{$\mathrm{P} 1$} & \multicolumn{7}{|c|}{$\mathrm{P} 2$} \\
\hline No. & $\mathrm{M}$ & $\mathrm{A}$ & $\mathrm{I}$ & $\mathrm{O}$ & $\mathrm{R}$ & Q & Category & $\mathrm{M}$ & $\mathrm{A}$ & I & $\mathrm{O}$ & $\mathrm{R}$ & $Q$ & Category \\
\hline$f_{1}$ & 0.3497 & 0.2331 & 0.1166 & 0.3006 & 0 & 0 & $\mathrm{M}$ & 0.3750 & 0.2125 & 0.1500 & 0.2625 & 0 & 0 & $\mathrm{M}$ \\
\hline$f_{2}$ & 0.1481 & 0.2099 & 0.2778 & 0.3642 & 0 & 0 & $\mathrm{O}$ & 0.1962 & 0.2595 & 0.2152 & 0.3291 & 0 & 0 & $\mathrm{O}$ \\
\hline$f_{3}$ & 0.2663 & 0.2485 & 0.1716 & 0.3136 & 0 & 0 & $\mathrm{O}$ & 0.3416 & 0.2360 & 0.1553 & 0.2671 & 0 & 0 & $\mathrm{O}$ \\
\hline$f_{4}$ & 0.1753 & 0.3636 & 0.1688 & 0.2922 & 0 & 0 & $\mathrm{~A}$ & 0.2000 & 0.3355 & 0.1548 & 0.3097 & 0 & 0 & $\mathrm{~A}$ \\
\hline$f_{5}$ & 0.1768 & 0.3598 & 0.2012 & 0.2622 & 0 & 0 & $\mathrm{~A}$ & 0.2188 & 0.2625 & 0.2125 & 0.3063 & 0 & 0 & $\mathrm{~A}$ \\
\hline$f_{6}$ & 0.2078 & 0.3571 & 0.1883 & 0.2468 & 0 & 0 & $\mathrm{~A}$ & 0.2405 & 0.2532 & 0.2025 & 0.3038 & 0 & 0 & $\mathrm{~A}$ \\
\hline$f_{7}$ & 0.3540 & 0.2360 & 0.1801 & 0.2298 & 0 & 0 & $\mathrm{M}$ & 0.3228 & 0.2658 & 0.1519 & 0.2595 & 0 & 0 & $\mathrm{M}$ \\
\hline$f_{8}$ & 0.2078 & 0.2468 & 0.3506 & 0.1948 & 0 & 0 & $\mathrm{I}$ & 0.1633 & 0.2789 & 0.3333 & 0.2245 & 0 & 0 & I \\
\hline$f_{9}$ & 0.2468 & 0.1948 & 0.1818 & 0.3766 & 0 & 0 & $\mathrm{O}$ & 0.2763 & 0.2171 & 0.1908 & 0.3158 & 0 & 0 & $\mathrm{O}$ \\
\hline & \multicolumn{7}{|c|}{$\mathrm{P} 3$} & \multicolumn{7}{|c|}{$\mathrm{P} 4$} \\
\hline No. & $\mathrm{M}$ & $\mathrm{A}$ & I & $\mathrm{O}$ & $\mathrm{R}$ & $\mathrm{Q}$ & Category & $\mathrm{M}$ & $\mathrm{A}$ & $\mathrm{I}$ & $\mathrm{O}$ & $\mathrm{R}$ & $\mathrm{Q}$ & Category \\
\hline$f_{1}$ & 0.3865 & 0.2147 & 0.1227 & 0.2761 & 0 & 0 & $\mathrm{M}$ & 0.3494 & 0.2229 & 0.1446 & 0.2831 & 0 & 0 & $\mathrm{M}$ \\
\hline$f_{2}$ & 0.1698 & 0.4277 & 0.1635 & 0.2390 & 0 & 0 & $\mathrm{O}$ & 0.1796 & 0.3713 & 0.1916 & 0.2575 & 0 & 0 & $\mathrm{O}$ \\
\hline$f_{3}$ & 0.3509 & 0.2632 & 0.1754 & 0.2105 & 0 & 0 & $\mathrm{O}$ & 0.3452 & 0.2321 & 0.1905 & 0.2321 & 0 & 0 & $\mathrm{O}$ \\
\hline$f_{4}$ & 0.2201 & 0.2516 & 0.1824 & 0.3459 & 0 & 0 & $\mathrm{~A}$ & 0.2750 & 0.2063 & 0.2000 & 0.3188 & 0 & 0 & $\mathrm{~A}$ \\
\hline$f_{5}$ & 0.2484 & 0.2422 & 0.1863 & 0.3230 & 0 & 0 & $\mathrm{~A}$ & 0.3063 & 0.2125 & 0.1750 & 0.3063 & 0 & 0 & $\mathrm{~A}$ \\
\hline$f_{6}$ & 0.2236 & 0.2360 & 0.1988 & 0.3416 & 0 & 0 & $\mathrm{~A}$ & 0.2756 & 0.2051 & 0.1859 & 0.3333 & 0 & 0 & $\mathrm{~A}$ \\
\hline$f_{7}$ & 0.3537 & 0.2195 & 0.1890 & 0.2378 & 0 & 0 & $M$ & 0.3313 & 0.2563 & 0.1813 & 0.2313 & 0 & 0 & $\mathrm{M}$ \\
\hline$f_{8}$ & 0.1887 & 0.2893 & 0.3270 & 0.1950 & 0 & 0 & $\mathrm{I}$ & 0.1925 & 0.3043 & 0.2671 & 0.2360 & 0 & 0 & $\mathrm{I}$ \\
\hline$f_{9}$ & 0.3013 & 0.2051 & 0.2308 & 0.2628 & 0 & 0 & $\mathrm{O}$ & 0.3457 & 0.2099 & 0.2222 & 0.2222 & 0 & 0 & $\mathrm{O}$ \\
\hline
\end{tabular}

Table 4 Quality attributes classification results in four periods

(Note: The incomplete and questionable questionnaires have been excluded, so the rate of R and Q is 0 .)

(4) Error analysis

To examine the precision of GM(1,1), we further test to determine the error between the predicted value and actual value. Following Eq. (16), we use GTMS3.0 to calculate the sum of residual squares and average relative error. The result of quality attribute $f_{9}$ is shown in Tab. 5 .

Table 5 Error analysis of the GM $(1,1)$ model

\begin{tabular}{|c|c|c|c|}
\hline \multirow{2}{*}{$\begin{array}{c}\text { Quality } \\
\text { category }\end{array}$} & $\begin{array}{c}\text { Sum of residual } \\
\text { squares }\end{array}$ & Value & Level \\
\cline { 3 - 4 } & 0.0000 & 0.0118 & 2 \\
\hline $\mathrm{M}$ & 0.0000 & 0.0177 & 2 \\
\hline $\mathrm{A}$ & 0.0004 & 0.0516 & 3 \\
\hline $\mathrm{I}$ & 0.0000 & 0.0042 & 1 \\
\hline $\mathrm{O}$ & \multicolumn{3}{|c}{} \\
\hline
\end{tabular}

Tab. 5 shows that all sums of residual squares approximate zero, and the average relative error is small, indicating that $\operatorname{GM}(1,1)$ model can perform fitting predictions.

(5) Predicting the quality attributes classification
Take must-be quality attribute of $f_{9}$ (see column $\mathrm{M}$ of each sub-table's last row) as an example, according to the time response function of $\operatorname{GM}(1,1)$ model, the predicted value for period 5 can be found as

$$
\begin{aligned}
& \hat{x}_{M}^{(1)}(k)=3.1894 \cdot \mathrm{e}^{0.1138(k-4)}-2.0193 \\
& \hat{x}_{M}^{(1)}(5)=\hat{x}_{M}^{(1)}(5)-\hat{x}_{M}^{(1)}(4)=1.5399-1.1701=0.3698
\end{aligned}
$$

Accordingly, the expected value of A, I, O for period 5 can be estimated as shown in Tab. 6. We can see the service quality attribute $f_{9}$ is predicted to be $\mathrm{M}$ in period 5 , as 0.3698 is the largest value in the rightmost column.

\subsection{Improving GM(1,1) Results with Markov Chain}

To obtain a more accurate prediction of dynamics in quality attributes classification in period 5, we employ the approach proposed in Section 3.3 to modify the $\operatorname{GM}(1,1)$ model: 
(1) Partition the states

We use the $\mathrm{M}$ (Must-be) sequence of $f_{9}$ in Tab. 6 to illustrate how to modify $\operatorname{GM}(1,1)$ with Markov chain. The forecasting of other quality attributes can be obtained similarly.

Table 6 Simulated value and predicted value of different quality attribute category of $f_{9}$

\begin{tabular}{|c|c|c|c|c|c|c|}
\hline Quality category & & Period 1 & Period 2 & Period 3 & Period 4 & Predicted \\
\hline \multirow{2}{*}{$\mathrm{M}$} & Actual & 0.2468 & 0.2763 & 0.3013 & 0.3457 & N/A \\
\hline & Simulated & 0.2468 & 0.2731 & 0.3060 & 0.3429 & 0.3698 \\
\hline \multirow{2}{*}{ A } & Actual & 0.1948 & 0.2171 & 0.2051 & 0.2099 & N/A \\
\hline & Simulated & 0.1948 & 0.2144 & 0.2107 & 0.2071 & 0.2035 \\
\hline \multirow{2}{*}{$\mathrm{I}$} & Actual & 0.1818 & 0.1908 & 0.2308 & 0.2222 & N/A \\
\hline & Simulated & 0.1818 & 0.1996 & 0.2142 & 0.2298 & 0.2414 \\
\hline \multirow{2}{*}{$\mathrm{O}$} & Actual & 0.3766 & 0.3158 & 0.2628 & 0.2222 & N/A \\
\hline & Simulated & 0.3766 & 0.3145 & 0.2637 & 0.2211 & 0.1853 \\
\hline
\end{tabular}

Table 7 The residual series of the "Must-be" sequence of $f_{9}$

\begin{tabular}{|c|c|c|c|c|c|}
\hline$k$ & $P_{1}$ & $P_{2}$ & $P_{3}$ & $P_{4}$ & $P_{5}$ \\
\hline$x_{M}^{(0)}(k)$ & 0.2468 & 0.2763 & 0.3013 & 0.3457 & \\
\hline$\hat{x}_{M}^{(0)}(k)$ & 0.2468 & 0.2731 & 0.3060 & 0.3429 & 0.3698 \\
\hline Residual & 0 & 0.0032 & -0.0047 & 0.0028 & \\
\hline
\end{tabular}

Using the Eq. (17), we derive Tab. 7. For the boundary value of residuals, i.e. $(-0.0047,0.0032)$, we use Eqs. (18)(20) to partition the residual into three states. That is,

State 1: $S_{1} \in[-0.0047,-0.0021]$

State 2: $S_{2} \in[-0.0021,0.0005]$

State 3: $S_{3} \in[0.0005,0.0032]$

We then match the last row of Tab. 7 to the above states, and summarize them in Tab. 8.

Table 8 The actual residual states and forecasted residual states in different

\begin{tabular}{|c|c|c|c|c|c|}
\hline$k$ & $P_{1}$ & $P_{2}$ & $P_{3}$ & $P_{4}$ & $P_{5}$ \\
\hline $\begin{array}{c}\text { The actual } \\
\text { residual sate }\end{array}$ & $S_{2}$ & $S_{3}$ & $S_{1}$ & $S_{3}$ & - \\
\hline $\begin{array}{c}\text { The forecast } \\
\text { residual sate }\end{array}$ & - & $S_{3}$ & $S_{1}$ & $S_{3}$ & $S_{1}$ \\
\hline
\end{tabular}

(2) Construct states transition matrix of quality attributes classifications

We can obtain the states' transferring frequency distribution in line with the state of residual in Tab. 8. Thus, we get the states transition matrix $P$ according to Eqs. (21)(22)

$$
P^{(1)}=\left[\begin{array}{lll}
0 & 0 & 1 \\
0 & 0 & 1 \\
1 & 0 & 0
\end{array}\right]
$$

(3) Determine the forecast value

MCGM $(1,1)$ model predictions in different periods are calculated based on the data in Tab. 7-8 and states interval value. For example, the residual is in State 2 (see Tab. 8) in the first period, based on the states transition matrix $P^{(1)}$, it is most likely that the next state would be State 3. And its corresponding residual interval value is $[0.0005,0.0032]$. Therefore, modified point prediction value of the second period could be obtained according to Eq. (23)

$$
\begin{aligned}
& \tilde{x}^{(m)}(2)=\hat{x}^{(m)}(1)+\frac{0.0005+0.0032}{2}= \\
& =0.2731+0.0019=0.2750
\end{aligned}
$$

Similarly, we can obtain point predictions for other periods, as is shown in Tab. 9.

Table 9 The modified prediction value of different periods

\begin{tabular}{|c|c|c|c|c|c|}
\hline$k$ & $P_{1}$ & $P_{2}$ & $P_{3}$ & $P_{4}$ & $P_{5}$ \\
\hline$x_{M}^{(0)}(k)$ & 0.2468 & 0.2763 & 0.3013 & 0.3457 & \\
\hline$\hat{x}_{M}^{(0)}(k)$ & 0.2468 & 0.2731 & 0.3060 & 0.3429 & 0.3698 \\
\hline$\tilde{x}_{M}^{(0)}(k)$ & & 0.2750 & 0.3026 & 0.3448 & 0.3664 \\
\hline $\begin{array}{c}\text { Fitting } \\
\text { error }\end{array}$ & & 0.0013 & -0.0013 & 0.0009 & \\
\hline
\end{tabular}

In the same way, we can calculate the prediction value for other attributes of $f_{9}$ ( e.g. A, O, I) in Tab. 10 .

Table 10 Point predictions for classification states (A, O, M and I) of $f_{9}$

\begin{tabular}{|c|c|c|c|c|}
\hline$k$ & $\mathrm{M}$ & $\mathrm{A}$ & $\mathrm{I}$ & $\mathrm{O}$ \\
\hline$P_{1}$ & - & - & - & - \\
\hline$P_{2}$ & 0.2750 & 0.2158 & 0.1953 & 0.3154 \\
\hline$P_{3}$ & 0.3026 & 0.2065 & 0.2268 & 0.2631 \\
\hline$P_{4}$ & 0.3448 & 0.2085 & 0.2255 & 0.2220 \\
\hline$P_{5}$ & 0.3664 & 0.1993 & 0.2540 & 0.1847 \\
\hline
\end{tabular}

Therefore, the states distribution vector of the quality attributes $f_{9}$ in the next period is obtained as follows: $T\left(f_{9}, 5\right)=\{0.3664,0.1993,0.1847,0.2540\}$

Clearly, quality attribute $f_{9}$ is a "Must-be" attribute at period 5 .

\subsection{Comparison of $\mathrm{GM}(1,1)$ and $\operatorname{MCGM}(1,1)$}

To differentiate the predicted results of GM $(1,1)$ and $\operatorname{MCGM}(1,1)$, we use two criteria to evaluate the proposed model. They are the absolute mean error (AME) and standard mean square error(SMSE):

$$
\begin{aligned}
A M E & =\frac{1}{n} \sum_{i=1}^{n}|\varepsilon(i)| \\
S M S E & =\sqrt{\frac{1}{n} \sum_{i=1}^{n} \varepsilon^{2}(i)}
\end{aligned}
$$

where, as discussed above, $\varepsilon(i)=x^{(0)}(i)-\hat{x}^{(0)}(i)$.Thus, we compare the accuracy of $\operatorname{GM}(1,1)$ to $\operatorname{MCGM}(1,1)$ for 
quality attribute $f_{9}$ in Tab. 11, It is clear that the MCGM $(1,1)$ model is more accurate.

Table 11 The comparison of the two models for $f$

\begin{tabular}{|c|c|c|c|}
\hline Category of $f_{9}$ & Models & AME & SMSE \\
\hline \multirow{2}{*}{$\mathrm{M}$} & $\mathrm{GM}(1,1)$ & 0.0039 & 0.0036 \\
\cline { 2 - 4 } & $\mathrm{MCGM}(1,1)$ & 0.0016 & 0.0010 \\
\hline \multirow{2}{*}{$\mathrm{A}$} & $\mathrm{GM}(1,1)$ & 0.0036 & 0.0032 \\
\cline { 2 - 4 } & $\operatorname{MCGM}(1,1)$ & 0.0014 & 0.0012 \\
\hline \multirow{2}{*}{$\mathrm{I}$} & $\operatorname{GM}(1,1)$ & 0.0083 & 0.0101 \\
\cline { 2 - 4 } & $\operatorname{MCGM}(1,1)$ & 0.0030 & 0.0034 \\
\hline \multirow{2}{*}{$\mathrm{O}$} & $\operatorname{GM}(1,1)$ & 0.0029 & 0.0046 \\
\cline { 2 - 4 } & $\operatorname{MCGM}(1,1)$ & 0.0002 & 0.0003 \\
\hline
\end{tabular}

\subsection{Predicting the Category for Each Quality Attribute}

Tab. 10 shows that the quality element classification of $f_{9}$ varies with time, as shown in Fig. 2 . We can see the quality attribute $f_{9}$ (i.e. Free storage within 7 days) follows the dynamics states, and Fig. 2 shows that the quality attribute categories from period 1 to period 5 are: "O $\rightarrow \mathrm{O} \rightarrow \mathrm{M} \rightarrow \mathrm{M} \rightarrow \mathrm{M}$ (predicted)". Thus, quality attribute $f_{9}$ will be treated as must-be quality attribute in the future (P5), and the express delivery firms should try their best to offer 7-day free storage to meet the customer expectation, as it is a "Must" (M) quality attribute.

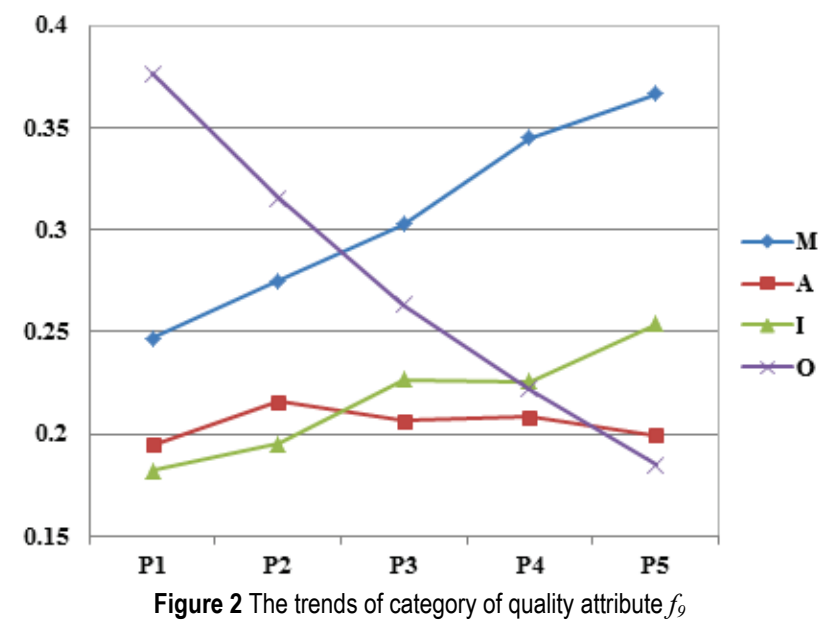

Table 12 The predicted values and classification results of all attributes

Table 12 The predicted values and classification results of all attributes
\begin{tabular}{|c|c|c|c|c|c|}
\hline No. & M & A & I & O & $\begin{array}{c}\text { Final } \\
\text { Category }\end{array}$ \\
\hline$f_{1}$ & $\mathbf{0 . 3 5 6 5}$ & 0.2258 & 0.1213 & 0.2968 & $\mathrm{M}$ \\
\hline$f_{2}$ & 0.1464 & $\mathbf{0 . 4 9 8 5}$ & 0.1465 & 0.1818 & $\mathrm{~A}$ \\
\hline$f_{3}$ & $\mathbf{0 . 3 4 9 1}$ & 0.2549 & 0.2134 & 0.1924 & $\mathrm{M}$ \\
\hline$f_{4}$ & 0.3124 & 0.1522 & 0.2318 & $\mathbf{0 . 3 4 9 6}$ & $\mathrm{O}$ \\
\hline$f_{5}$ & $\mathbf{0 . 3 5 2 9}$ & 0.1966 & 0.1461 & 0.3087 & $\mathrm{M}$ \\
\hline$f_{6}$ & 0.2689 & 0.1918 & 0.1822 & $\mathbf{0 . 3 5 9 7}$ & $\mathrm{O}$ \\
\hline$f_{7}$ & $\mathbf{0 . 3 5 6 3}$ & 0.2165 & 0.2166 & 0.2170 & $\mathrm{M}$ \\
\hline$f_{8}$ & 0.2177 & $\mathbf{0 . 3 0 8 0}$ & 0.2645 & 0.2136 & $\mathrm{~A}$ \\
\hline$f_{9}$ & $\mathbf{0 . 3 6 6 4}$ & 0.1993 & 0.2540 & 0.1847 & $\mathrm{M}$ \\
\hline
\end{tabular}

In addition, from the perspective of life cycle of quality attributes, $f_{9}$ partially verified the model of life cycle for successful quality attributes $(\mathrm{I} \rightarrow \mathrm{A} \rightarrow \mathrm{O} \rightarrow \mathrm{M})$, which were proposed by Kano [3] and Löfgren et al. [9]. Because we can take the life cycle of $f_{9}(\mathrm{O} \rightarrow \mathrm{O} \rightarrow \mathrm{M} \rightarrow \mathrm{M} \rightarrow \mathrm{M})$ as part of life cycle for successful quality attributes $(\mathrm{I} \rightarrow \mathrm{A} \rightarrow \mathrm{O} \rightarrow \mathrm{M})$ considering the different testing of time interval.

In the same manner, we estimate the value of each category for each quality attribute, $f_{1}-f_{9}$, and show the predicted value in Tab. 12. Compared to Fig. 2, the dynamic tendency of classification for quality attributes $f_{1}-f_{8}$ can also be described.

\subsection{Discussions}

From the results of Section 4.6, we have the following observations:

(1) The proposed MCGM $(1,1)$ model does not require much historical data as the prediction methods (e.g. time series, forecasting method based on statistics ), when predicting the future states of quality attributes classification. The MCGM $(1,1)$ model can significantly reduce the workload and cost of the companies. For instance, in the case studied, we find quality attributes information of four periods is sufficient to predict the next period's quality state.

(2) Most of the express delivery quality attributes are dynamic, i.e. their categories deriving from Kano model change with time. The quality element $f_{1}$ (On time delivery) and $f_{7}$ (Low price) have the stable classification in the five periods: "M $\rightarrow \mathrm{M} \rightarrow \mathrm{M} \rightarrow \mathrm{M} \rightarrow \mathrm{M}$ ", which follow the life cycle of stable quality attributes identified by Kano [3] and Löfgren et al. [9]. The roles of these quality attributes are not expected to change quickly to any great extent since they are the "must" quality and the key benefits for customers buying the service.

(3) Recall in Tab. 14, we have the following quality attributes dynamics: $f_{3}$ (Quality assurance) "O $\rightarrow \mathrm{M} \rightarrow \mathrm{M} \rightarrow \mathrm{M} \rightarrow \mathrm{M}$ "; $\quad f_{4} \quad$ (Convenient tracking) "A $\rightarrow \mathrm{A} \rightarrow \mathrm{A} \rightarrow \mathrm{O} \rightarrow \mathrm{O}$ "; $\quad f_{5} \quad$ (Membership benefits) "A $\rightarrow \mathrm{O} \rightarrow \mathrm{O} \rightarrow \mathrm{M} \rightarrow \mathrm{M}$ "; $f_{6}$ (Complaints handled timely) "A $\rightarrow \mathrm{O} \rightarrow \mathrm{O} \rightarrow \mathrm{O} \rightarrow \mathrm{O}$ "; $\quad f_{8} \quad$ (Highly qualified staffs) $\mathrm{I} \rightarrow \mathrm{I} \rightarrow \mathrm{I} \rightarrow \mathrm{A} \rightarrow \mathrm{A}$ ", and $f_{9}$ (Free storage within 7 days) "O $\rightarrow \mathrm{O} \rightarrow \mathrm{M} \rightarrow \mathrm{M} \rightarrow \mathrm{M}$ ". They partially proved the life cycle of successful quality attributes $(\mathrm{I} \rightarrow \mathrm{A} \rightarrow \mathrm{O} \rightarrow \mathrm{M})$ observed by Kano [3] and Löfgren et al. [9]. As discussed above, they do not completely match the life cycle of successful quality attributes probably due to differences between product/service and time-duration in the product/service life cycle.

(4) Moreover, quality attribute $f_{2}$ (Door-to-door pick up): "'O $\rightarrow \mathrm{O} \rightarrow \mathrm{A} \rightarrow \mathrm{A} \rightarrow \mathrm{A}$ ", does not follow any life cycle (i.e. Successful, flavor and stable ) in Kano [3] and Löfgren et al. [9]. In fact, it reverses the direction of the dynamics prescribed in the life cycle of successful quality attributes, as mentioned in Löfgren et al. [9]. One explanation for this is that service quality attribute "Door-to-door pick up" underwent major changes between 2008 and 2013. With the advance of IT, i.e. RFID, Bar Code and GIS, more novel service can be added to attract customers further, which leads to a reverse shift in the lifecycle. In other words, our study suggests there may be other alternative life cycles in the service industry, particularly in the express delivery service.

(5) The rightmost column of Tab.12 shows quality attributes $f_{1}, f_{3}, f_{5}, f_{7}$ and $f_{9}$ are "must-be" quality attributes in the next time period. They are the basic requirements (order qualifier) for express delivery firms, thus they are necessary but probably not sufficient for firm success. Attributes $f_{4}$ and $f_{6}$ have the faster (the more response) feature; they are the key service attributes for advertising 
and achieving competitive advantages. Thus, firms should try their best to provide these service quality attributes and ensure high quality. Finally, attributes $f_{2}$ and $f_{8}$ need to be the "attractive" quality attributes in next time period; they are the order winner and give firms the competitive advantages in attracting new customers.

\section{CONCLUSIONS AND SUGGESTIONS}

In this study, we employ the grey theory and Markov chain to propose an integrated approach, MCGM $(1,1)$, to forecast the dynamics of service quality attributes with limited data. Further, we explored the life cycles of service quality attributes suggested by Kano [3] and Löfgren et al. $[4,9]$. MCGM(1,1) model makes the best use of $\operatorname{GM}(1,1)$ model (efficient in forecasting under limited information), and Markov chain (effective in manipulating fluctuations). The proposed method uses Kano model to classify customer requirement, grey theory to forecast with limited data and Markov chain to enhance the predicted accuracy. It also forecasts customer requirement in a quantitative and dynamic way, providing a more practical and specific perspective on customer requirement analysis. The proposed MCGM(1,1) model can help marketing departments know in advance the changes of the dynamics of service quality (the evolution trends), and satisfy customers' requirements based on the future state that would bring potential business opportunity. In this way, correct resource could be put into the right customer requirements at the right time. The application of the proposed method to the Chinese express delivery industry shows that it is a more effective prediction tool. The main contributions of this work can be summarized as follows:

(1) The dynamics and life cycles of quality attributes, introduced by Kano [3], is an important research topic of theory of attractive quality [7,9]. We not only provide evidence for the dynamics of quality life cycle from Kano model through an empirical investigation, but also propose a low cost alternative of predicting various life cycles of service quality attributes.

(2) The MCGM(1,1) model is feasible, well-structured and effective, taking the advantages of $\operatorname{GM}(1,1)$ model with forecasting using limited data and Markov chain in manipulating fluctuations. So the method brings about cost savings and efficient way for managers to better understand the service quality attributes evolution trends.

(3) The empirical investigation of Chinese express delivery industry has given evidence to the existence of two quality life cycles: successful quality attributes and stable quality attributes. However, our data do not support the existence of the life cycle of flavor-of-the month quality attributes. This is different from the results found in Kano $[3,7,9]$. Moreover, we found that there may exist other types of quality life cycles.

The existing approach has some limitations, which can be further improved. First, the time interval for obtaining the data in the empirical study is relatively short, which may affect the prediction accuracy of the model. A longer time period may be necessary to test a specific type of quality life cycle. Second, our data are limited to region of Yangtze River Delta. To test the applicability of the proposed approach and better understand the dynamics of delivery service quality, it may be beneficial to include data from other regions. Finally, more testing work may be conducted to examine reliability and validity in other industries.

\section{REFERENCES}

[1] Prahalad, C. K. \& Ramaswamy, V. (2000). Co-opting customer competence. HarvardBusiness Review, 78(1), 7990.

[2] Kano, N., Seraku, F., Takahashi, S. H., \& Tsjui H. H. (1984). Attractive quality and must-be quality. Hinshitsu, 14(2), 147-156. https://doi.org/10.20684/quality.14.2_147

[3] Kano, N. (2001). Life cycle and creation of attractive quality. Paper presented at the fourth International QMOD Conference on Quality Management and Organisational Development, University of Linköping, Linköping.

[4] Löfgren, M. \& Witell, L. (2008). Two decades of using Kano's theory of attractive quality: a literature review. The Quality Management Journal, 15(1), 59-75. https://doi.org/10.1080/10686967.2008.11918056

[5] Rahaju, D. E. S. \& Dian R. S. D. (2011). Dealing with Dissatisfaction Measure in QFD Model to Derive Target of Engineering Characteristics. International Journal of Industrial Engineering, 18(12), 634-644.

[6] Luor, T., Lu, H.-P., Chien, K.-M., \& Wu, T.-C. (2015). Contribution to quality research: A literature review of Kano's model from 1998 to 2012. Total Quality Management \& Business Excellence, 26(3-4), 234-247. https://doi.org/10.1080/14783363.2012.733264

[7] Nilsson-Witell, L. \& Fundin, A. (2005). Dynamics of service attributes: a test of Kano's theory of attractive quality. International Journal of Service Industry Management, 16(2), 152-168. https://doi.org/10.1108/09564230510592289

[8] Zhao, M. \& Dholkia, R. R. (2009). A multi-attribute model of web site interactivity and customer satisfaction. Managing Service Quality, 19(3), 286-307. https://doi.org/10.1108/09604520910955311

[9] Löfgren, M., Witell, L., \& Gustafsson, A. (2011). Theory of attractive quality and life cycles of quality attributes. The TQM Journal, 23(2), 235-246. https://doi.org/10.1108/17542731111110267.

[10] Rahario, H. (2007). Deling with Kano model dynamics: Strengthening the Quality Function Deployment as a design for Six Sigma tool. Jurnal Teknik Industri, 9(1), 15-26. https://doi.org/10.9744/jti.9.1.pp.\%2015-26

[11] Raharjo, H., Brombacher, A. C., Goh, T. N., \& Bergman, B. (2010). On integrating Kano's model dynamics into QFD for multiple product design. Quality and Reliability Engineering International, 26(4), 351-363. https://doi.org/10.1002/qre.1065

[12] Shen, X. X., Xie, M., \& Tan, K. C. (2001). Listening to the future voice of the customer using fuzzy trend analysis in QFD. Quality Engineering, 13(3), 419-425. https://doi.org/10.1080/08982110108918670

[13] Chong, Y. T. \& Chen, C. H. (2010). Management and forecast of dynamic customer needs: an artificial immune and neural system approach. Advanced engineering informatics, 24(1), 96-106. https://doi.org/10.1016/j.aei.2009.06.003

[14] Song, W., Ming, X., \& Xu, Z. (2013). Integrating Kano model and grey-Markov chain to predict customer requirement states. Proceedings of the Institution of Mechanical Engineers, Part B: Journal of Engineering. https://doi.org/10.1177/0954405413485365

[15] Shahin, A., Pourhamidi, M., Antony, J., \& Hyun Park, S. (2013). Typology of Kano models:a critical review of literature and proposition of a revised model. International Journal of Quality \& Reliability Management, 30(3),341358. https://doi.org/10.1108/02656711311299863 
[16] Lee, Y.-C. \& Huang, S.-Y. (2009). A new fuzzy concept approach for Kano's model. Expert Systems with Applications, 36(3), 4479-4484. https://doi.org/10.1016/j.eswa.2008.05.034

[17] Wang, C. H. (2013). Incorporating customer satisfaction into the decision making process of product configuration a fuzzy Kano perspective. International Journal of Production Research, 51(22), 6651-6662. https://doi.org/10.1080/00207543.2013.825742

[18] Meng, Q., Jiang, X., \& Bian, L. (2015). A decision-making method for improving logistics services quality by integrating fuzzy Kano model with importance-performance analysis. Journal of Service Science and Management, 8(3), 322-331. https://doi.org/10.4236/jssm.2015.83034

[19] Choi, T. M., Hui, C. L., Liu, N., Ng, S. F., \& Yu, Y. (2014). Fast fashion sales forecasting with limited data and time. Decision Support Systems, 59, 84-92. https://doi.org/10.1016/j.dss.2013.10.008

[20] Parasuraman, A., Zeithaml, V. A., \& Berry, L. L. (1988). SERVQUAL: a multiple-item scale for measuring consumer perception of service quality. Journal of Retailing, 64(1), 1240.

[21] Li, G. D., Yamaguchi, D., \& Nagai, M. (2007). A GM $(1,1)$ - Markov chain combined model with an application to predict the number of Chinese international airlines. Technological Forecasting and Social Change, 74(8), 14651481. https://doi.org/10.1016/j.techfore.2006.07.010

\section{Contact information:}

Qingliang MENG, Professor (Corresponding author)

School of Management \& Economics,

Jiangsu University of Science and Technology,

301, Xuefu Road, Zhenjiang, Jiangsu 212 013, China

E-mail: mengzhi007@163.com

Zhijie Sasha DONG, Associate Professor

Industrial Engineering Program, Ingram School of Engineering,

Texas State University,

601 University Dr, San Marcos, TX 78666, United States

E-mail: sasha.dong@txstate.edu

\section{Lin HE, Postgraduate}

School of Management \& Economics,

Jiangsu University of Science and Technology,

301, Xuefu Road, Zhenjiang, Jiangsu 212 013, China

E-mail: 466657381@qq.com

Jing DONG, Postgraduate

School of Management \& Economics

Jiangsu University of Science and Technology,

301, Xuefu Road, Zhenjiang, Jiangsu 212 013, China

E-mail: 951374917@qq.com 